\title{
Performance Analysis of different Routing Protocol for WSN
}

\author{
Vijeta Kumawat \\ Research Scholar \\ Jayoti Vidyapeeth Women's \\ University, Jaipur (Raj.), India
}

\author{
Kavita, PhD \\ Guide \\ Jayoti Vidyapeeth Women's \\ University, Jaipur (Raj.) India
}

\author{
Banta Singh Jangra, $\mathrm{PhD}$ \\ Co-Guide \\ FGM Govt. PG College, \\ Haryana, India
}

\begin{abstract}
Wireless Sensor Networks (WSN) has vital research issues in communication. WSN network has sensor and communicating node which are placed in remote areas to sense and send the recorded data to base station. Routing protocols are network layer protocol which discovers the best available path from source node to destination node. The packet loss problem can be happen due to transmission errors, broken links and no route to the destination and these problem is analyzed using different routing and mobility parameters. In this paper, research work is to implement different routing protocol of wireless sensor network on ns-2 simulators and analyze the performance of quality of services issues in terms of performance parameters as Packet Delivery Ratio v/s routing protocol and Packet Delivery Ratio v/s mobility.
\end{abstract}

\section{Keywords}

WSN, DSDV, OLSR, AODV.

\section{INTRODUCTION}

Wireless sensor networks are used in remote areas as military applications, industrial applications and conjointly in personal space networks where permanent infrastructure cannot be possible. WSN devices use of infrared or oftenest signals to transfer info and resources between devices one another. WSN network routing can be classified into proactive and reactive routing [1]. For discovery and maintenance of path form source to destination is done by routing protocol [2].

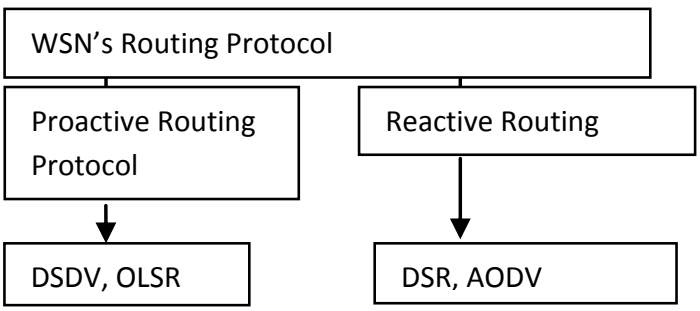

Fig 1: Classification chart of WSN routing protocol

proactive routing protocols update routing table frequently on fixed interval so that route of other node are always recently known while reactive routing protocol activated their route discovery process whenever need of sending data[3,4]. This paper is identify the performances of different routing protocols such as DSDV, AODV and OLSR for WSN Network on performance parameter such as average end-toend delay, packet delivery ratio and routing overhead evaluated on simulation with NS-2.34 simulator.

Classification of Routing Protocols for WSN is as shown in Fig 1.

\section{PROPOSED WORK}

ADOV, DSDV and OLSR are very common routing protocol for WSN network but hard to decide the optimal network under different network condition as mobility speed. So WSN Network is simulated in NS2.34 with simulation parameter mentioned in table 1 and different quality of services (QOS) parameters are evaluated for identification of optimal routing for WSN network.

\section{A. Destination Sequence Distance Vector Routing Protocol}

DSDV routing protocol is distance vector, table driven based on Bellman ford routing procedure. Destination Sequence Distance Vector is a type of proactive routing process in which problem of counting to infinity with sequence number is avoided [9]. In DSDV, routing table has information for each entry such as destination ip address, destination sequence number, next-hop IP address and hop-count. This routing protocol uses two types message for route updates such as full dump and incremental packet. The full dump packet carries all the routing information of the network but incremental packet carries only the information changed. DSDV routing creates large amount of overhead due to the periodic update message. Every time interval each node in the network broadcast to its neighbor its current sequence number with any routing table updates $[5,6]$.

B. Optimized Link State Routing Protocol (OLSR) The Optimized Link State Routing Protocol (OLSR) is optimized version of link state routing protocol in which nodes are divided into link type and neighbor type. link type is defined for the state of the link and the neighbor type is defined for the state of the neighbor including MPR information. So first type node reasonability is to maintain the information about the link between a node and all its neighbors [7]. In HELLO messages, a node transmits all information about its links to neighbor nodes and on receiving of HELLO message from a neighbor, it checks to see if the IP address of the interface at which the message was received is contained in the HELLO message or not. If not then A new entry is created and it is checked whether a corresponding neighbor entry exists or not, if not then a corresponding neighbor entry is also created. According to the validity time received in the HELLO message, an asymmetric timer is also updated [8]. This timer will be responsible to decide the duration for which the link entry will be considered asymmetric if the symmetric timer expires. If the HELLO message contains the address of the receiving interface, the symmetric timer for that interface is updated. Also the status of link is updated if required. According to this link, if necessary, the neighbor entry is also updated. Out of the symmetric timer and asymmetric timer, whichever is maximum, is set as the actual holding time for this entry. In neighbor detection 1-hop neighbor repositories are 
maintained. This task is achieved by only using the main addresses of nodes. Whenever there are changes observed in the link-set, OLSR updates the neighbor entries as well. The corresponding neighbor entry gets deleted whenever a linkentry is deleted (only if there is no other existing link entry for that neighbor) $[9,10]$.

\section{Adhoc on Demand Vector (AODV) Routing}

AODV is a reactive nature of routing in which route discovery starts whenever demanded [11] and Sequence number is increased by node if new node is established to the node. Higher sequence number means to the fresh routes [12] in WSN and for avoiding routing loop problem in AODV. Changes in network topology and Problem of link breakages are responded in a timely manner. Long time unused route are deleted from routing tables. A RREQ is recognized by the pair source address and request ID. Every time when the source node sends a new RREQ then the request ID is incremented. After receiving request message, every node verifies the request ID and source address pair. The latest RREQ is rejected, if there is already RREQ packet with same pair of parameters. If there is any node with no route entry for the destination then it rebroadcasts the RREQ with incremented hop count parameter. A route reply (RREP) message is generated and sent back to source if a node has route with sequence number greater than or equal to that of RREQ. On having a valid route to the destination or if the node itself is the destination then a RREP message is sent to the source by the node. For each routing table entry, information of predecessor nodes is maintained which is used for forwarding the Route Reply packet to source route. Whenever the nexthop link breaks happens, these predecessor nodes are notified with RERR packets. Each predecessor node in turn forwards the R_Request packet to its own set of predecessors, thus effectively erasing all routes using the broken link [13].

\section{RESULTS AND DISCUSSION}

Experiments are performed on NS-2 simulator and evaluated the Packet Delivery Ratio (PDR), Average End-to-End Delay (ETE) and Routing Overhead (RO) for DSDV, OLSR and AODV Routing. The results of experiments are shown in table 2.

Table 1. Simulation Parameters in Experiment

\begin{tabular}{|l|l|}
\hline Parameter in Experiment & Value of Parameter \\
\hline Simulator Version & NS-2.34 \\
\hline $\begin{array}{l}\text { Time Duration for } \\
\text { Simulation }\end{array}$ & 1 minute \\
Number of Nodes in & 20 \\
\hline Area & $\begin{array}{l}\text { Rectangle 1000 meter X } \\
1000 \text { meter }\end{array}$ \\
\hline Traffic Type & CBR(Constant Bit Rate) \\
\hline Size of Data Packet & $\mathbf{1 0 0 0 B}$ \\
\hline Wifi Model & IEEE 802.11(b) \\
\hline Mobility Model used & $\begin{array}{l}\text { Random WayPoint } \\
\text { MobilityModel }\end{array}$ \\
\hline $\begin{array}{l}\text { Variation in Routing Protocol } \\
\text { Used }\end{array}$ & DSDV, OLSR and AODV \\
\hline
\end{tabular}

Table 2. Experimental Results of Routing Overhead v/s Routing Protocols

\begin{tabular}{|l|l|l|l|l|}
\hline $\begin{array}{l}\text { Routing } \\
\text { Protocol }\end{array}$ & $\begin{array}{l}\text { Data } \\
\text { Packets }\end{array}$ & $\begin{array}{l}\text { Control } \\
\text { Packets }\end{array}$ & $\begin{array}{l}\text { Total } \\
\text { packets }\end{array}$ & $\begin{array}{l}\text { Routing } \\
\text { Over } \\
\text { head }\end{array}$ \\
\hline DSDV & 100 & 2575 & 2675 & 0.9626 \\
\hline OLSR & 100 & 1702 & 1802 & 0.9445 \\
\hline AODV & 100 & 496 & 596 & 0.8322 \\
\hline
\end{tabular}

Table 3. Experimental Results of PDR v/s Routing Protocols

\begin{tabular}{|l|l|l|l|}
\hline $\begin{array}{l}\text { Routing } \\
\text { protocol }\end{array}$ & $\begin{array}{l}\text { Data } \\
\text { Packets }\end{array}$ & $\begin{array}{l}\text { Received } \\
\text { Packet }\end{array}$ & PDR\% \\
\hline DSDV & 100 & 97 & 97.00 \\
\hline OLSR & 100 & 98 & 98.00 \\
\hline AODV & 100 & 99 & 99.00 \\
\hline
\end{tabular}

Table 4. Experimental Results of ETE v/s Routing Protocols

\begin{tabular}{|l|l|l|}
\hline Routing Protocol & Data Packets & ETE \\
\hline DSDV & 100 & $1.0 \mathrm{~ms}$ \\
\hline OLSR & 100 & $0.9 \mathrm{~ms}$ \\
\hline AODV & 100 & $1.3 \mathrm{~ms}$ \\
\hline
\end{tabular}

\section{CONCLUSION}

In this paper we have evaluated the performance of wsn network using different routing OLSR DSDV and AODV on scale of QOS parameters as Routing overhead, PDR and Average Delay. From the results it is concluded that proactive routing protocol such as DSDV and OLSR, each node maintains up-to-date routing information in the network. So connection setup times are fast and end to end delay is less than AODV but these routing protocols have large amount of routing overhead due to frequent update message in network. On demand routing protocol such AODV reduces the traffic in network but introduces delay due to route discovery process on demand and AODV routing protocol is achieved highest PDR compared to OLSR and DSDV so it is highly adaptable in WSN.

\section{REFERENCES}

[1] Anshul Khairwal, Kumar Abhishek, Surya Prakash, Tej Pratap, 2012 A Comprehensive Study of Various Biometric Identification Techniques, in International Conference on ICCCNT, IEEE.

[2] M.N Lima, A.L. Dos, Guy Pujolle.2009 A Survey of Survivability in Mobile Ad Hoc Networks. IEEE Communications Surveys and Tutorials. 
[3] Suparana Das Gupta, Soumyabrata Saha, Souvick Ghosh 2010 LORP: Least Overhead Routing Protocol for MANET, In International Conference on Wireless Communication \& Sensor Computing, IEEE.

[4] Kamal K. Chouhan, Amit Kumar et. al.2010 Securing on- Demand Source Routing in MANETs, In International Conference on Computer and Network Technology, pp.294-297, IEEE.

[5] A. Suresh, K. Duraiswamy, 2010 Scalable Instant way point routing protocol for MANET, In International Conference on Computing , Communication and Networking Technologies, IEEE.

[6] Shima, Hassan, Patel, Razali, 2010 Comparative Review Study of Reactive and Proactive Routing Protocols in MANETs, In International Conference on Digital Ecosystems and Technologies, pp. 304- 309, IEEE.

[7] Jabbehdari, Shamaei et. al.2010 IQos-ODMRP: A Novel routing Protocol Considering Qos Parameter in MANET, In International Symposium on Industrial Electronics and Applications, pp. 126-130, IEEE.

[8] Srinivas Sethi, Udgata, 2010 Scalable Cluster Based on Ad hoc -on Demand Distance Vector Routing Protocol for MANET, IEEE.
[9] Mangrulakar and Atique, 2010 Trust Based Secured Adhoc on Demand Distance Vector routing protocol for mobile adhoc network, IEEE.

[10] N. Adam, M.Y, Ismail, Abdullah, 2012 Effect of Node Density on Performances of three MANET routing protocol, In International Conference on Electronic Devices, Systems and Applications, pp.321-325, IEEE.

[11] Kannhavong, H. Nakayama, N. Kato, Y. Nemoto, and A. Jamalipour,2006 Analysis of the node isolation attack against olsr-based mobile ad hoc networks, In International Symposium on Computer Networks, pages 30 - 35, IEEE.

[12] J. Orset and A. Cavalli, 2006 A security model for olsr manet protocol, In 7th International Conference on Mobile Data Management, page 122, IEEE.

[13] Kumari, Neelu, Sandeep Kumar Gupta, Rajni Choudhary, and Shubh Laxshmi Agrwal. 2016 New performance analysis of AODV, DSDV and OLSR routing protocol for MANET. In Computing for Sustainable Global Development (INDIACom), 2016 3rd International Conference on, pp. 33-35. IEEE. 